\title{
Dynamic time analysis of glass fiber reinforced polymer - numerical simulation and experiment
}

\author{
Zuzana Murčinková, \\ Technical University of Košice, Faculty of Manufacturing Technologies with seat in Prešov, \\ Bayerova 1, 08001 Prešov, \\ Slovak Republic
}

Received: May 20, 2020. Revised: June 29, 2020. Accepted: June 30, 2020. Published: June 30, 2020.

\begin{abstract}
Composites are known for their significant damping, however, both reinforcement type or layered arrangement influence the response of material: mechanical, thermal, electrical etc. The paper provides the dynamic time analysis of glass fiber reinforced polymer samples of various layups. The mechanical response to dynamic excitation was tested by numerical simulation and experiment. The excitation function was the unit impulse force generating free damped vibrations. Experimental results were evaluated in time domain to obtain damping parameters. For numerical simulation, the commercial software was used to visualize deformed model in individual damping phases, Mises stress distribution in individual laminate layers, and comparison of that for different layups.
\end{abstract}

Keywords - damping coefficient, decay, direction, fiber, layer.

\section{INTRODUCTION}

$\mathrm{D}$ ynamic response of any material is important in many applications. The composite material micro-structure implies particles and short fibers (straight, curved, waved, continuous fibers). called reinforcing elements and they cause improvement of the physical properties. The useful combination of reinforcing elements (shape, size, volume fraction of reinforcing elements, arrangement etc.) and matrix can form material with required properties.

The estimation of static properties of mixed matrix and reinforcement by analytical, numerical, experimental, and hybrid approaches have been preferably topic of research. Researchers have been making efforts in the effective numerical simulation and the suitable estimation of the mechanical properties, such as Young's modulus of elasticity, the shear modulus, and Poisson's ratio, of anisotropic materials for different shapes and reinforcement arrangements.

A summary of the current state of numerical methods can be found in [1]-[5] focusing on static properties. However, to understand, estimate, and control the dynamic and damping properties of different type of composite structures is essential for the effective use of composites in industrial applications.

The numerical approaches for dynamic modelling (not material damping) based on various computational methods have been developed and try to overcome the difficulties of inner complexity of composite materials models [6], [7].

The experiments investigating the damping parameters and vibration characteristics depending on fiber orientations in different layup was performed in [8]-[10]. Reference [11] stated that position and the percentage of the fibers are the most influencing factors for damping and natural frequency. Moreover, in [8] is stated that damping and vibration characteristics are strongly influenced by fiber orientation and moreover, natural frequency and damping ratio increase from $0^{\circ}$ to $45^{\circ}$ of fiber orientation.

The methods for the experimental investigation of energy dissipation response are direct or indirect. In this study, the indirect method, i.e. the method of free damped vibrations based on time domain response was used. Depending on the evaluation method, material and geometry of samples and goal of testing, the various measurement setups were developed for testing. Some researchers have developed an iterative numerical-experimental scheme [12].

\section{Materials}

The samples are made of glass fiber reinforced polymer (GFRP) with polymer matrix. Dimensions of samples are: $115 \times 115$ of average thickness 3-layered samples $1,1725 \mathrm{~mm}$. The fabric is twill, i.e. bidirectional, weave $\left(280 \mathrm{~g} / \mathrm{m}^{2}\right.$, twill $2 / 2$ ). The arrangement of layers is different in order to test influence of inner composition to damping. The horizontal orientation of warp corresponded to $0^{\circ}$, Fig, 1 . 


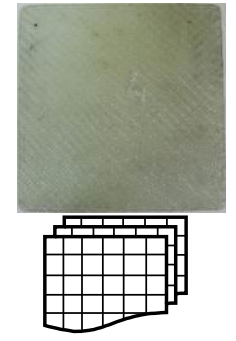

$0,0,0$
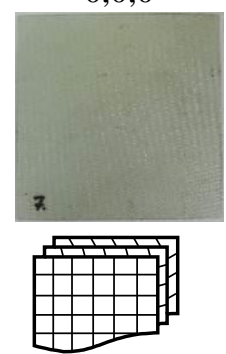

$0,15,30$

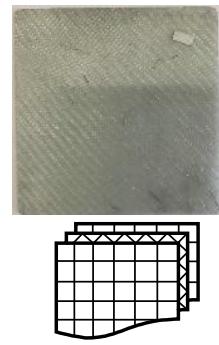

$0,45,0$

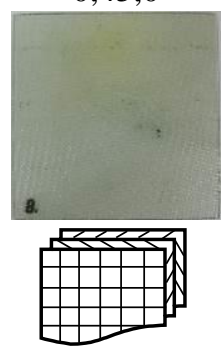

$0,60,120$

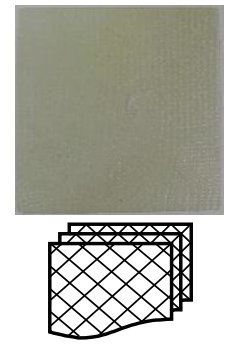

$45,45,45$

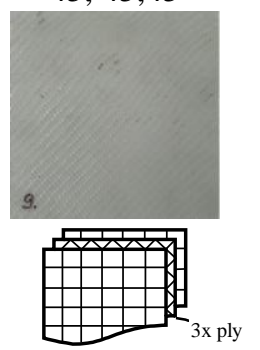

$0,45,45,45,0$
Fig. 1 GFRP samples and its inner arrangement

III. NUMERICAL SIMULATION - DYNAMIC TIME ANALYSIS - AND RESUlTS

Numerical model involves following assumptions: matrix is consider to be ideal, i.e. without cavities and impurities; an adhesion between fibers and matrix is ideal, The numerical model does not consider weave of fabric.

The p-version ("p" depicts polynomial) of the Finite Element Method (FEM) implemented in the Creo Simulate module of the PTC Creo Parametric System was used. In pversion of FEM the mesh of finite elements stay the same during the every iteration called p-loop pass and the required convergence is achieved by increasing the polynomial order of the polynomial shape functions at required elements [13] up to $9^{\text {th }}$ order in Creo Simulate. The finite elements used in Creo Simulate are called p-elements. Thus the shape of p-elements can differ from ideal shape and lower mesh density can be used comparing to h-elements in h-version of FEM.

The main steps for Dynamic Time Analysis of numerical model of laminate, i.e. layered structure. The procedure is similar for most of commercial software; however, it can differ in detail. The commercial software implements the classical lamination theory (more in e.g. [14].) The following procedure and result windows are for the numerical finite element analysis of laminate composite material model and dynamic time analysis by Creo Simulate (version 4):

\section{A. Defining the axes of material orientation regarding global coordinate system}

Since laminates are materials characterized by different material properties in different directions, we must define the main material axes. Usually the material axis 1 is identical with the orientation of the reinforcing fibers. In our case, the samples involve layers of a bidirectional fabric with a twill weave of weight $280 \mathrm{~g} / \mathrm{m}^{2}$. Axes 1 and 2 will be the axes of fabric warp and weft, direction 3 is the direction perpendicular to the fabric, Fig. 2.

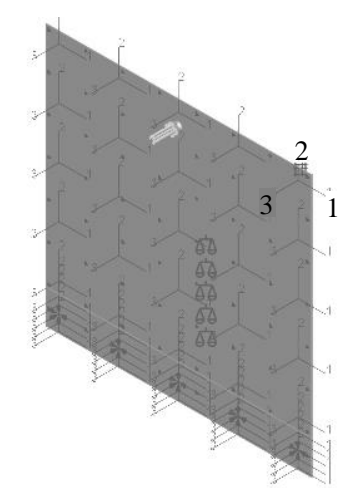

Fig. 2 Axes of material orientation; 1, 2 (warp and weft directions)

\section{B. Defining the material properties of one lamina (one layer).}

The laminate can be defined as a transverse isotropic material, the plane of isotropy is plane 12 (axes orientation is in Fig. 2). The material constants are the Young's modulus of elasticity in the direction $1,2,3$, the Poisson's ratio and the shear modulus of elasticity in the planes 12, 23, 13. Material constants can be determined analytically, experimentally or numerically using the concept of a representative volume element.

In our case, we determined the material constants analytically using the Rule of Mixture as follows: We had six different samples differing by their layup, Fig. 1. Finding the dimensions and weight of samples, the density was determined: $1.345 \mathrm{~g} / \mathrm{cm}^{3}$. In general, volume percent of fibers is $35 \%$ and resin consumption $232 \mathrm{~g} / \mathrm{m}^{2}$ for standard hand laminate. It corresponds for our sample $0,0,0$. For our samples, average fiber and matrix volume percentage was $V_{\mathrm{f}}=29 \%$ a $V_{\mathrm{m}}$ $=71 \%$. Then

$$
\begin{aligned}
E_{1} & =V_{\mathrm{f}} E_{\mathrm{f}}+V_{\mathrm{m}} E_{\mathrm{m}}= \\
& =0.29 \times 71 \mathrm{GPa}+0.71 \times 3.5 \mathrm{GPa}=23.075 \mathrm{GPa}
\end{aligned}
$$

where $E_{\mathrm{f}}$ and $E_{\mathrm{m}}$ are Young's modules of elasticity of E-glass fiber and matrix, respectively. Since it is a bidirectional fabric, it can be considered: $E_{1}=E_{2}$. Then $E_{3}$

$E_{3}=\frac{E_{\mathrm{m}}}{1-V_{\mathrm{f}}\left(1-\frac{E_{\mathrm{m}}}{E_{\mathrm{f}}}\right)}=4.832 \mathrm{GPa}$

Poisson's ratio is:

$\mu_{12}=V_{\mathrm{f}} \mu_{\mathrm{f}}+V_{\mathrm{m}} \mu_{\mathrm{m}}=$

$$
=0.29 \times 0.22+0.71 \times 0.33=0.2981=0.3
$$

where $\mu_{\mathrm{f}}$ and $\mu_{\mathrm{m}}$ are Poisson's ratio of E-glass fibers and matrix, respectively. With respect to the transverse isotropy $\mu_{21}$ and $\mu_{31}$ are the same as Poisson's ratio of matrix, i.e. 0.33.

Shear modulus of elasticity is:

$$
G_{12}=\frac{G_{\mathrm{m}}}{1-V_{\mathrm{f}}\left(1-\frac{G_{\mathrm{m}}}{G_{\mathrm{f}}}\right)}=\frac{1.25 \mathrm{GPa}}{1-0.29\left(1-\frac{1.25 \mathrm{GPa}}{30 \mathrm{GPa}}\right)}=1.731 \mathrm{GPa}
$$

where $G_{\mathrm{f}}$ and $G_{\mathrm{m}}$ are shear modules of elasticity of E-glass fibers and matrix, respectively. With respect to the transverse isotropy $G_{13}$ and $G_{23}$ are the same as shear modules of elasticity of matrix. 


\section{Defining of laminate layup.}

The laminate layup is characterized by several parameters such as the number of layers, layer thickness, orientation in the global coordinate system. The mentioned parameters was assigned for corresponding sample layup.

\section{Shell definition by assigning the layup and material axes orientation to model.}

3-dimentional model used the composite shell elements (111 triangles and 310 quadrilaterals, Fig. 3b). That elements consist of one or more materials whose properties may vary through the thickness of the shell.

\section{E. Boundary conditions definition.}

A predefined impulse function is added as the excitation function. This is the so-called The Dirac delta function, which has a value of one at the point of excitation, which corresponds to the impact of a modal hammer in measuring. The numerical model with boundary conditions is shown in Fig. 3a.

F. Defining of mesh density and Measures for dynamic analysis.

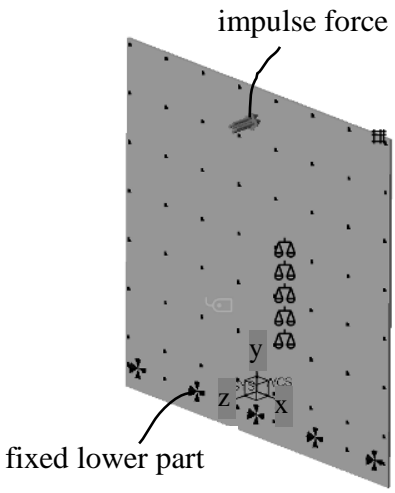

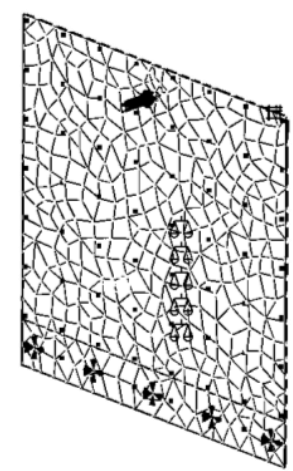

b
Fig. 3 FEM model (a) and mesh of 421 shell finite p-elements (b)

Maximum finite p-element size was set to $8 \mathrm{~mm}$ in whole model. The final mesh created by automatic geometric element mesher (AutoGEM) is in Fig. 3b. Combination of triangles and quadrilaterals is default option for shell elements generation. In areas where AutoGEM cannot use quadrilateral elements due to the model geometry, Creo Simulate use triangular elements as fillers. For meshing, the default settings (e.g. aspect ratio and maximum edge turn) of AutoGEM were used. The higher density of mesh is not applied as in "critical" areas the convergence and accuracy is obtained by use of higher polynomial order (up to $9^{\text {th }}$ order).

Output measures for the dynamic time analysis are displacement, displacement in the direction of the $\mathrm{Z}$ axis (direction of impulse force, see Fig. 3a), Mises stress, vibration velocity and acceleration.

When defining a dynamic time analysis, one of input quantities is the damping coefficient entered in percent. The mentioned coefficient is a damping ratio according to [15]. The disadvantage is that damping coefficient is an input quantity and therefore it is not possible to determine the damping coefficient (i.e. damping ratio $\zeta$ ) using numerical analysis, as it is able to do in the laboratory experiment. The following Fig. 4 compares the time response depending on different damping coefficients. The material is the same for each graph in Fig. 4.
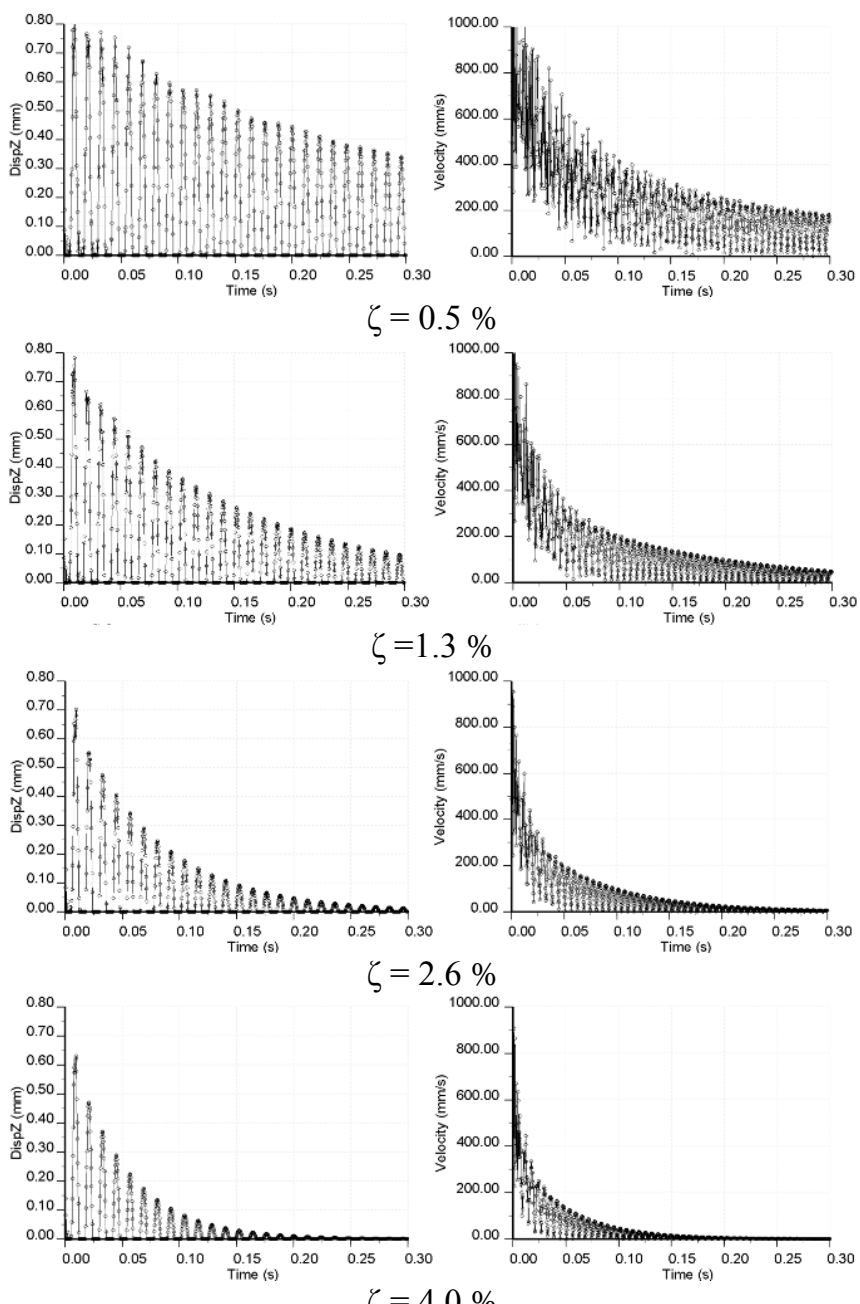

$\zeta=4.0 \%$

Fig. 4 Comparison of displacements (only positive ones are shown) and velocity for different damping ratio values in time period $0-0.3 \mathrm{~s}$

The following Fig. 5 compares the behavior of laminate samples with its individual damping ratios estimated in laboratory experiment during free damped vibration decay. The vales in right side of graphs are the amplitudes $(\mathrm{mm})$ in time $0.998 \mathrm{~s}$.

Naturally, in case of different fiber orientation in individual layers the stress field distribution is different in each layer. Mises stress field distribution for sample 0,15,30 in individual plies 1, 2, 3 and in all plies is provided in Fig. 6. The stress field is not symmetrical although the boundary conditions are symmetrical. It is caused by material arrangement. 

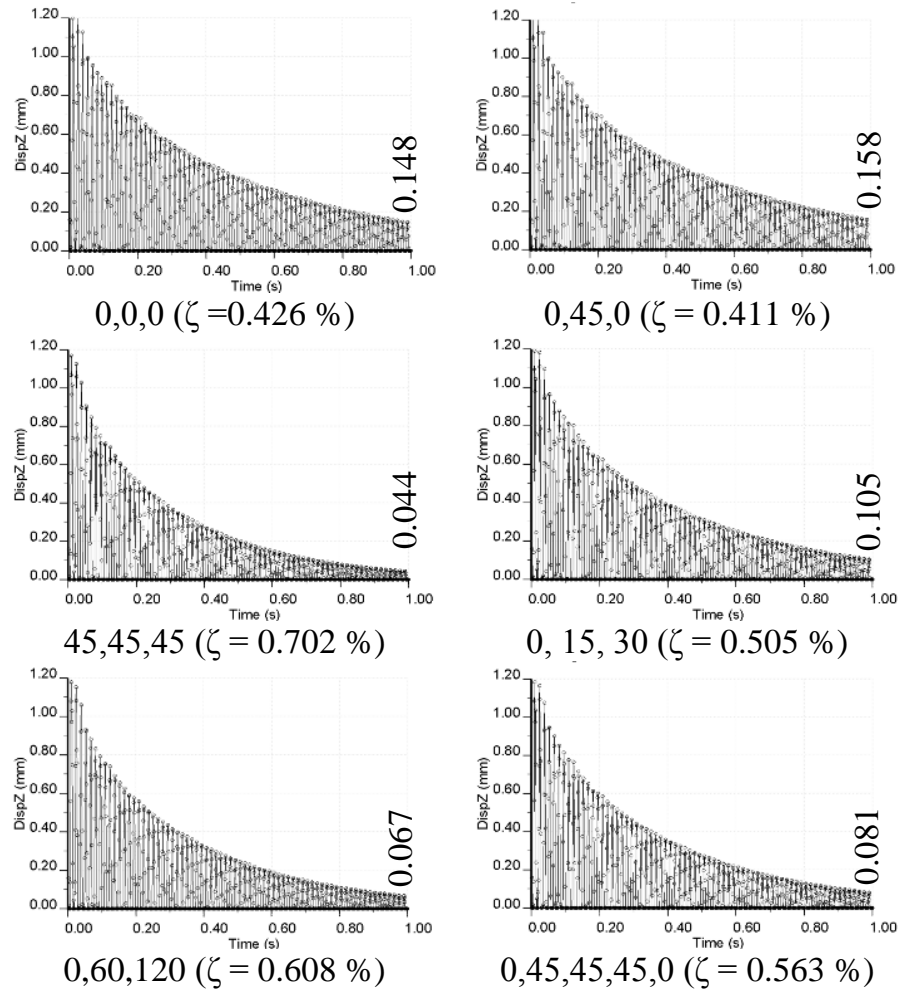

Fig. 5 Displacement in direction of impulse force in time period 0-1s for individual samples and its experimentally determined damping ratios

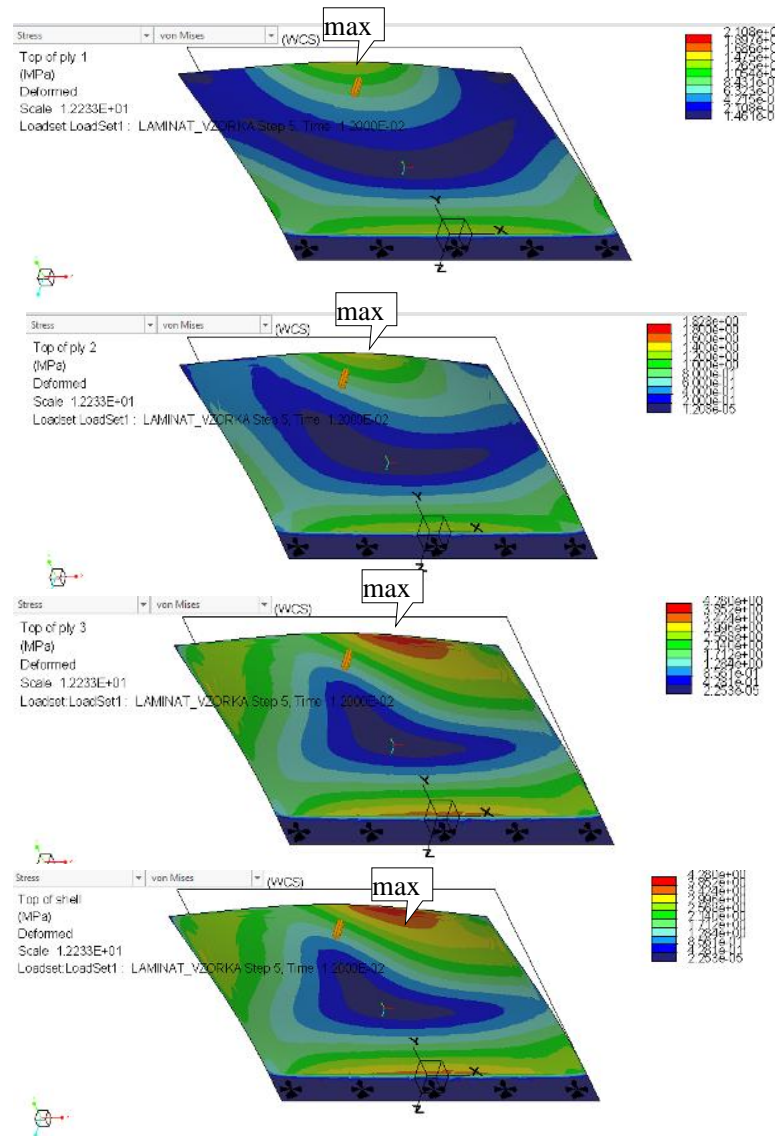

ply 1

ply 2

ply 3 the maximum of first amplitude of sample $0,15,30$

\section{LABORATORY EXPERIMENT AND RESULTS}

The samples were fixed (Fig. 3a) in jaw-vice and excited using the impulsive type of the excitation generated by the modal hammer NI PCB. The equal impulse force was applied in the perpendicular direction (Fig. 3a, z-axis direction) to initiate beam vibrations. One side of the laminate samples is free to vibrate. The excited vibrations were free damped vibrations that were scanned by Polytec laser vibrometer. The laser beam point of vibrations recording was situated in point of modal hammer excitation. The obtained data were recorded using signal processing software LabVIEW. The time domain curves (example in Fig. 7) that has character of the exponential decaying response was obtained for each sample.

The damped free vibrations are the quasi-periodic because the amplitude $X_{\mathrm{i}}$ of the previous vibration cycle is not the same as the subsequent one $X_{\mathrm{i}+1}$. The decay of vibration amplitudes is exponential. The denser vibration cycles at the beginning of plot in Fig. 7 are the unsteady short period just after hammer bump.

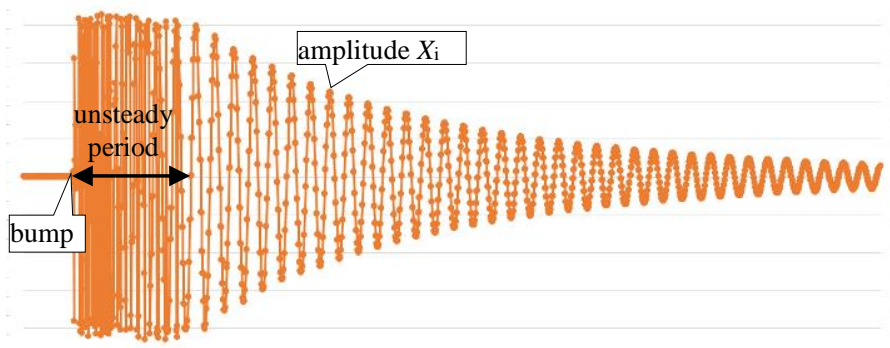

Fig. 7 Time domain decaying response (Velocity vs. Time)

The damping parameters (logarithmic decrement $\delta$ and damping ratio $\zeta$ ) were determined by the method of free damped vibrations based on time domain response (Fig. 7). According to mentioned method, the logarithmic decrement $\delta$ was calculated over a number of cycles $n$ from time domain response

$\delta=\frac{1}{n} \ln \left(\frac{X_{i}}{X_{i+n}}\right)$

where $X_{\mathrm{i}}$ and $X_{\mathrm{i}+\mathrm{n}}$ are the $i$-th and $(i+n)$-th amplitudes values of the $i$-th and $(i+n)$-th vibration cycles, respectively. The logarithmic decrement $\delta$ was estimated using $n=30,60$ and 100 cycles and its averaging.

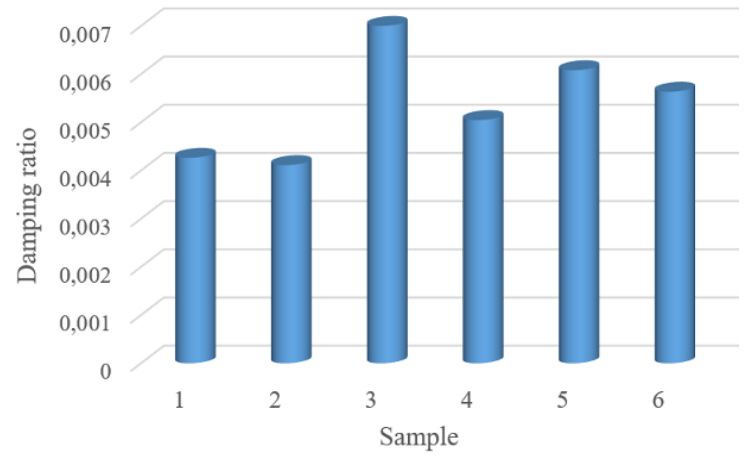

Fig. 8 Experimentaly estimated damping ratios $(1-0,0,0 ; 2-0,45,0$; $3-45,45,45 ; 4-0,15,30 ; 5-0,60,120 ; 6-0,45,45,45,0)$ 
Subsequently indirectly from logarithmic decrement $\delta$ the damping ratios $\zeta$ was estimated using (6)

$$
\zeta=\frac{1}{\sqrt{1+\frac{4 \pi^{2}}{\delta^{2}}}}
$$

Damping ratio can be estimated also directly from frequency domain curve by the half-power bandwidth method [16]. Damping ratios for individual samples from Fig. 1 are in Fig. 8. See also [17].

\section{CONCLUSIONS}

The response to dynamic excitation differs depending on inner material arrangement. It is confirmed by different damping ratios obtained by equal force excitation and boundary conditions. Composites are characterized by the possibility of achieving a different internal structure having a equal volume percentage of fibers. The damping is different at the same fiber volume percentage $\left(V_{\mathrm{f}}=29 \%\right)$. This was proved both experimentally.

Benefits of simulation are: 1. visualization of different response due to damping at the same material in period $0-0.3 \mathrm{~s}$ (Fig. 4), 2. visualization of different responses in period $0-1 \mathrm{~s}$ of the same sample composition but different layup orientation (Fig. 5), 3. visualization of stress distribution in individual layers of sample in first maximum amplitude (Fig. 6), 4. visualize deformed model shape in individual damping phases (deformed model is visible in Fig. 6)

Using commercial computational software is unable to estimate the damping parameters as the experiment allows. The damping can be only input value of dynamic numerical analysis. It is disadvantage of numerical modeling in field of estimation of material damping.

Moreover, the facts referred in introduction were confirmed: 1. Damping parameters depend on fiber orientation in different layups, even in case of same material composition (not arrangement) and same volume percentage of fibers, 2 . Damping parameters increase from $0^{\circ}$ to $45^{\circ}$. In our case damping had the highest value for layer orientation $45,45,45$.

\section{ACKNOWLEDGMENT}

The author would like to thank the Agency of Ministry of Education, Science, Research and Sport of the Slovak Republic for supporting this research through the grant of VEGA 1/0910/17. This work was supported by the Slovak Research and Development Agency under Contract No. APVV-18-0316.

\section{References}

[1] B.D. Agarwal, L.J. Broutman, K. Chandrashekhara, Analysis and performance of fibre composites. John Wiley \& Sons; 2016.

[2] E. Kormaníková, M. Žmindák, and P. Sabol. "Tensile Properties of Carbon Fiber Reinforced Polymer Matrix Composite." In International Conference on Computational \& Experimental Engineering and Sciences, pp. 763-770. Springer, Cham, 2019.
[3] M. Žmindák, P. Novák, and V. Dekýšs. "Analysis of bond behaviour in strengthened reinforced concrete beam with carbon fiber reinforced polymer lamella." In MATEC Web of Conferences, vol. 107, p. 00045. EDP Sciences, 2017.

[4] J. Winczek, J. Iwaszko and M. Matuszewski, "Numerical analysis of thermal phenomena during surface heat treatment of $\mathrm{AlZn} 5.5 \mathrm{MgCu}$ aluminum alloy by GTA welding method." In Machine Modelling and Simulations 2019. 2019.

[5] V. Kompiš, Z. Murčinková, and M. Očkay. "Temperature fields in short fibre composites." In Computational modelling and advanced simulations, Springer, Dordrecht, 2011, pp. 99-116.

[6] J. Bocko, P. Lengvarský, "Bending vibrations of carbon nanotubes by using nonlocal theory,". In Procedia Engineering. 2014; 96: pp. 21-27.

[7] D.I. Milosavljevic, A. Sapietová, M. Žmindák, V. Dekýš, and P. Novák, "Dynamic modelling of elastic plates reinforced by strong fibres." IOP Conference Series: Materials Science and Engineering 776(1), 4th Slovak-Polish International Scientific Conference on Machine Modelling and Simulations (MMS 2019), Liptovský Ján; Slovakia.

[8] Ö.Y. Bozkurt, M. Zhou, Ö. Özbek, "Effect of Fibre Orientations on Damping and Vibration Characteristics of Basalt Epoxy Composite Laminates," In Proceedings of the World Congress on Civil, Structural, and Environmental Engineering (CSEE'16) March 30 - 31, 2016, Prague, Czech Republic.

[9] H. Abramovich, D. Govich, A. Grunwald, "Damping measurements of laminated composite materials and aluminum using the hysteresis loop method." in Progress in Aerospace Sciences, 78, 2015, pp. 8-18.

[10] P. Nagasankar, S.B. Prabu, R. Velmurugan, R., "The Influence of the Different Fiber lay-ups on the Damping Characteristics of Polymer Matrix Composite." in Journal of Applied Sciences, 12(10), 2012, pp. 1071-1074.

[11] A. Treviso, B. Van Genechten, D. Mundo, M. Tournour, "Damping in composite materials: Properties and models." in Composites Part B. 78, 2015, pp.144-152.

[12] G.D. Gounaris, E. Antonakakis, and C.A. Papadopoulos, Hysteretic damping of structures vibrating at resonance: An iterative complex eigensolution method based on damping-stress relation. Computers \& structures 85 , no. 23-24, 2007, pp. 18581868.

[13] R. Toogood, Creo Simulate Tutorial Release 1.0 \& 2.0: Structure/Thermal. SDC Publications, 2012.

[14] J.N. Reddy, Mechanics of laminated composite plates and shells: theory and analysis. CRC press, 2003.

[15] R. Jakel, Linear Dynamic System Analyses with Creo SimulateTheory \& Application Examples, Capabilities, Limitations, 9thSAXSIM 2017, TU Chemnitz, 28.03.2017. Available: https://monarch.qucosa.de/api/qucosa\%3A20722/attachment/AT $\underline{\mathrm{T}-0 /}$

[16] C.W. De Silva, Vibration damping, control, and design. CRC Press, 2007.

[17] Sayyid H. Hashemi Kachapi, Nonclassical Vibration Analysis of Piezoelectric Nanosensor Conveying Viscous Fluid, WSEAS Transactions on Applied and Theoretical Mechanics, pp. 252271, Volume 14, 2019,

Zuzana Murčinková (Slovakia, Prešov, 1973) is an associate professor in the field of Production Machinery at Technical University of Košice. $\mathrm{PhD}$ degree is in field Applied Mechanics and Master of Science degree is in Mechanical Engineering. She focuses on the fields of applied mechanics, production machinery, manufacturing technologies, mechanics of materials, static and dynamic simulation of mechanical 
behavior of structures using the finite element method. These fields of research are multidisciplinary joined in the field of applications, design and testing of composite materials. She is the lead author and co-author of 11 scientific papers in Current Content journals, 1 monography in renowned foreign publishers, 3 university textbooks and more than 80 scientific papers in the Web of Science and Scopus databases and more than 145 citations in Web of Science and Scopus databases.

\section{Creative Commons Attribution License 4.0 (Attribution 4.0 International , CC BY 4.0)}

This article is published under the terms of the Creative Commons Attribution License 4.0

https://creativecommons.org/licenses/by/4.0/deed.en_US 